valves previously used in surgical aortic valve replacement. While long term data on these newer generation valves does not yet exist to compare durability between these two groups, it is possible to compare hemodynamic profiles with the use of doppler echocardiography post-operatively.

Our study sought to evaluate the effect of aortic valve type implanted on both max peak gradient (maxPG), and mean peak gradient (meanPG) across the aortic valve post-operatively, taking account of valve size used intraoperatively; through the use of a prospective, non-randomized, interventional study.

Methods Patients who received a biologic aortic valve replacement between July 2017 and May 2021 in our centre were studied by echocardiography in the early post-operative period. Patients who received a sutureless aortic valve, and those who died prior to post-operative echocardiogram were excluded. The remaining population comprised 106 patients (Avalus $=23$, Inspiris $=9$ ). Other valves $(n=74)$ including Edwards Lifesciences Perimount Magna Ease $(n=14)$, LinaNova Aortic pericardial heart valve $(n=22)$, Medtronic Mosaic Bioprosthesis $(n=22)$, Medtronic Mosaic Ultra Bioprosthesis $(n=6)$, St Jude Trifecta $(n=9)$ and St Jude Epic bioprosthesis $(n=1)$ were grouped and analysed collectively as older generation aortic valves.

Results Edwards Lifesciences ${ }^{\circledR}$ Inspiris ResiliaTM were associated with statistically significant lower meanPGs in comparison to the meanPGs seen after implantation of Medtronic ${ }^{\circledR}$ Avalus ${ }^{\mathrm{TM}}$ Bioprosthesis of the same size $(\mathrm{p}=0.001)$. In addition to this, despite the small sample size analysed, a statistically significant difference was seen in post-operative meanPGs between the Inspiris and the previous generation bioprosthetic aortic valves $(p=0.007)$, taking the contributory effect of valve size on pressure gradient into account. In contrast, there appeared to be no statistically significant difference in hemodynamics post Avalus in comparison to the older generation bioprosthetic aortic valves.

Conclusions Limitations of this study included the potential effect of other confounding factors such as ejection fraction and patient's body surface area on post-operative doppler gradients, that were not accounted for in this study. Despite this, and the small sample size analysed, the results seen from Inspiris bioprosthesis appear promising in this small pilot study; showing favourable flow-gradient patterns at time of early post-operative transthoracic echocardiogram, in comparison to the flow-gradient patterns seen post-operatively following implantation of previous generation aortic valves.

\section{UTILISATION AND YIELD OF GENETIC TESTING AT AN INHERITED CARDIAC CONDITIONS CLINIC}

C Galvin, M Gallagher, H Cronin, C McGorrian, T Prendiville, J Galvin. Mater Misericordiae University Hospital/University College Dublin/Family Heart Screening Clinic, Dublin, Ireland

\subsection{6/heartjnl-2021-ICS.22}

Background This study was undertaken to compare the proportions of conditions referred/detected in probands of at-risk families at a single Inherited Cardiac Conditions (ICC) clinic and to assess the uptake of genetic testing and the yield of actionable genetic testing results in these individuals.

Methods In this retrospective study, we interrogated the clinic's proband database $(n=1,817$; representing a total of 3,316 condition-affected persons) in July 2020. We extracted data about those whose primary diagnosis was one of six ICCs: Hypertrophic Cardiomyopathy (HCM; n=444), Dilated Cardiomyopathy (DCM; $n=235)$, Long QT Syndrome (LQTS; $\mathrm{n}=220$ ), Arrhythmogenic Cardiomyopathy (ACM; n=30), Brugada Syndrome $(\mathrm{BrS} ; \mathrm{n}=25)$ and Catecholaminergic Polymorphic Ventricular Tachycardia (CPVT; $n=9$ ). We also included Sudden Adult Death Syndrome (SADS; $\mathrm{n}=165$ ) as an additional category. Genetic variants which were classified as Pathogenic (P), Likely Pathogenic (LP) and Variant of Uncertain Significance (VUS) by American College of Medical Genetics were grouped together as 'not negative'. $P$ and LP variants are directly clinically actionable while VUSs are not.

Conclusion The overall utilisation of genetic testing was relatively low at $32.4 \%$ in this cohort. The overall not negative (P, LP or VUS) rate for genetic testing across the ICCs probands in whom genetic testing was pursued was $60.7 \%$. Combined $\mathrm{P} / \mathrm{LP}$ variant rates within the not negative group in the larger cohorts of HCM $(n=86)$ and LQTS $(n=88)$ were $82.5 \%$ and $84.7 \%$ respectively. VUS rates vary from $0 \%$ to

\begin{tabular}{|c|c|c|c|c|c|c|c|c|c|}
\hline \multicolumn{10}{|c|}{ Abstract 22: Results } \\
\hline Condition & $n=$ & $\begin{array}{l}\text { No } \\
\text { Genetics }\end{array}$ & Genetics & $\begin{array}{l}\text { Genetics - } \\
\text { ve }\end{array}$ & $\begin{array}{l}\text { Genetics not - } \\
\text { ve }\end{array}$ & Pathogenic* & $\begin{array}{l}\text { Likely } \\
\text { Path* }\end{array}$ & VUS* & $\begin{array}{l}>1 \\
\text { variant }\end{array}$ \\
\hline HCM & 444 & $\begin{array}{l}290 \\
(65.3 \%)\end{array}$ & $\begin{array}{l}154 \\
(34.7 \%)\end{array}$ & $68(44.2 \%)$ & $86(55.8 \%)$ & $58(67.4 \%)$ & $13(15.1 \%)$ & $\begin{array}{l}14 \\
(16.3 \%)\end{array}$ & 10 \\
\hline DCM & 235 & $\begin{array}{l}193 \\
(82.1 \%)\end{array}$ & $42(17.9 \%)$ & $15(35.7 \%)$ & $27(64.3 \%)$ & $9(33.3 \%)$ & $11(40.7 \%)$ & $7(25.9 \%)$ & 5 \\
\hline LQTS & 220 & $98(44.5 \%)$ & $\begin{array}{l}122 \\
(55.5 \%)\end{array}$ & $37(30.3 \%)$ & $85(69.7 \%)$ & $51(60 \%)$ & $21(24.7 \%)$ & $\begin{array}{l}13 \\
(15.3 \%)\end{array}$ & 9 \\
\hline ACM & 30 & $17(56.7 \%)$ & $13(43.3 \%)$ & $3(23 \%)$ & $10(77 \%)$ & $6(60 \%)$ & $1(10 \%)$ & $3(30 \%)$ & 1 \\
\hline $\mathrm{BrS}$ & 25 & $18(72 \%)$ & $7(28 \%)$ & $2(28.6 \%)$ & $5(72.4 \%)$ & $2(40 \%)$ & $3(60 \%)$ & $0(0 \%)$ & 0 \\
\hline CPVT & 9 & $6(66.7 \%)$ & $3(33.3 \%)$ & $1(33.3 \%)$ & $2(66.7 \%)$ & $2(100 \%)$ & $0(0 \%)$ & $0(0 \%)$ & 0 \\
\hline SADS & 165 & $\begin{array}{l}140 \\
(84.8 \%)\end{array}$ & $25(15.2 \%)$ & $18(72 \% \%)$ & $7(28 \%) \wedge$ & $0(0 \%)$ & $0(0 \%)$ & $7(100 \%)$ & 0 \\
\hline Total & 1128 & $762(67.6)$ & $\begin{array}{l}366 \\
(32.4 \%)\end{array}$ & $\begin{array}{l}144 \\
(39.3 \%)\end{array}$ & $222(60.7 \%)$ & $128(57.7 \%)$ & $49(22.1 \%)$ & $\begin{array}{l}44 \\
(19.8 \%)\end{array}$ & 25 \\
\hline
\end{tabular}

'Genetics -ve' and 'Genetics not -ve'\%s calculated from the 'Genetics' totals. 'Pathogenic', 'Likely Pathogenic' or 'VuS'\%s calculated from the 'Genetics not -ve' totals. *Where multiple variants were detected in a single individual, their most pathogenic variant was recorded in this table. SADS patients with a P or LP variant were moved to the appropriate other condition. 
$30 \%$ within the not negative groups (excluding SADS where it was $100 \%)$. Factors contributing to low rates of genetic testing and phenotypic predictors of positive genotype warrant further investigation.

\section{Moderated posters}

\section{REAL-LIFE USE OF IMPELLA ${ }^{\circledR}$ CP: THE NORTHERN IRISH EXPERIENCE}

U Azhar Khan, M Saad Ahmed, J Conleth Murphy. Royal Victoria Hospital, Belfast, UK

\subsection{6/heartjn-2021-ICS.23}

Introduction The Impella ${ }^{\circledR}$ CP (ABIOMED Inc., Danvers MA, USA) is a relatively novel percutaneously inserted mechanical circulatory support (MCS) system. It is a $14 \mathrm{Fr}$ micro-axial temporary left ventricular assist device, which provides continuous forward flow of up to $4.3 \mathrm{~L} / \mathrm{min}$ into the ascending aorta to augment cardiac output. It is indicated to provide additional haemodynamic support in cases of advanced cardiogenic shock (CS), primarily in acute myocardial infarction (AMI). It is also used in selected high-risk patients undergoing complex percutaneous coronary intervention (PCI). It is a widely known modality but data from randomized controlled trials (RCT's) have not demonstrated a clear clinical benefit. We aim to describe our experience with use of Impella ${ }^{\circledR} \mathrm{CP}$ in our institution.

Methods The Belfast Health \& Social Care Trust is a high-volume interventional centre, which performs approximately 2500-3000 PCI per annum, of which 650 are emergency procedures. We retrospectively reviewed all patients who were treated with Impella ${ }^{\circledR} \mathrm{CP}$ for cardiogenic shock after acute myocardial infarction as well as those undergoing elective high-risk PCI [table 1]. We report patient demographics,

\begin{tabular}{|c|c|c|c|}
\hline & Total cases & $\begin{array}{c}\text { Acute MI with } \\
\text { Cardiogenic Shock }\end{array}$ & Elective High-risk PCl \\
\hline Number of patients & 7 & 5 & 2 \\
\hline Age (years) (Range) & $56.4(37-76)$ & $49.8(37-68)$ & $73(70-76)$ \\
\hline Male sex, $n(\%)$ & $7(100)$ & $5(100)$ & $2(100)$ \\
\hline Hypertension, $\mathrm{n}(\%)$ & $7(100)$ & $1(20)$ & $2(100)$ \\
\hline Dyslipidemia, $n(\%)$ & $3(43)$ & $1(20)$ & $2(100)$ \\
\hline Diabetes Mellitus, $\mathrm{n}(\%)$ & $2(28)$ & $0(0)$ & $2(100)$ \\
\hline Ischemic heart disease, $n(\%)$ & $1(14)$ & $0(0)$ & $1(50)$ \\
\hline \multicolumn{4}{|l|}{ Procedure-related complications } \\
\hline Limb Ischemia, n (\%) & $2(28)$ & $2(40)$ & $0(0)$ \\
\hline $\begin{array}{l}\text { Bleeding requiring transfusion, } n \\
\text { (\%) }\end{array}$ & $2(28)$ & $1(20)$ & $1(50)$ \\
\hline \multicolumn{4}{|l|}{ Before device placement } \\
\hline $\begin{array}{l}\text { Intra-aortic balloon pump before } \\
\text { Impella placement, } n(\%)\end{array}$ & $5(72)$ & $5(100)$ & $0(0)$ \\
\hline $\begin{array}{l}\text { Lactate }(\mathrm{mmol} / \mathrm{L}) \text {, median } \\
(\mathrm{Q} 1, \mathrm{Q} 3)\end{array}$ & & $6.2(2.6,6.7)$ & - \\
\hline Arterial pH, median $\left(\mathrm{Q}_{1}, \mathrm{Q}_{3}\right)$ & & $7.18(7.15,7.22)$ & - \\
\hline \multicolumn{4}{|l|}{$\begin{array}{l}\text { In-hospital treatment \& } \\
\text { outcome }\end{array}$} \\
\hline Surgical LVAD placement, $n(\%)$ & $1(14)$ & $1(20)$ & $0(0)$ \\
\hline $\begin{array}{l}\text { Extracorporeal membrane } \\
\text { oxygenation (ECMO), } n(\%)\end{array}$ & $2(28)$ & $2(28)$ & $0(0)$ \\
\hline $\begin{array}{l}\text { Length of stay in survivors (days), } \\
\text { mean (Range) }\end{array}$ & $70.2(5-185)$ & $110.3(55-185)$ & $10(5-15)$ \\
\hline 30-day mortality, $n(\%)$ & $2(28)$ & $2(40)$ & $0(0)$ \\
\hline
\end{tabular}

Abstract 23 Table 1 Baseline characteristics, procedure-related complications, in-hospital treatment and outcomes of all impella cases including patients with acute myocardial infarction (MI)/ cardiogenic shock and elective high-risk percutaneous coronary intervention $(P C)$

device-related complications and clinical outcomes in these cohorts.

Results Since March 2018, 7 patients have received Impella ${ }^{\circledR}$ CP support. 5 patients presented with AMI complicated by CS, and the remainder 2 had elective high-risk PCI. Mean age in the CS cohort was 49.8 years, with an average of one case every 232 days. Mean age in the elective high-risk PCI cohort was 73 years. In the CS cohort, 3 patients were subsequently transferred to a quaternary transplant centre with subsequent advanced heart failure (HF) input (2 extracorporeal membrane oxygenation and 1 surgical left ventricular assist device). 1 CS patient was transferred but did not undergo advanced HF input and was palliated. 1 CS patient died in the cathlab. In the total cohort $4 / 7$ (56\%) of patients had direct devicerelated complications (2/7 limb ischaemia, 2/7 bleeding requiring blood transfusions). Overall 30-day mortality in the CS cohort was $40 \%(2 / 5)$.

Conclusion Impella ${ }^{\circledR} \mathrm{CP}$ use in our high-volume center is infrequent and carries a high complication rate. Overall mortality rate in our CS group remains high but it is difficult to make definitive conclusions on small numbers. Our complication rate is significant, but similar to previous documented series in higher-volume centres. Impella ${ }^{\circledR} \mathrm{CP}$ may have clinical benefits in carefully selected patients, but in the absence of data from robust multi-centre RCT's patient selection will remain speculative. The exact role for Impella ${ }^{\circledR} \mathrm{CP}$ remains unclear.

\section{SHOCKWAVE INTRAVASCULAR LITHOTRIPSY AS AN ADJUNCT TO PERCUTANEOUS CORONARY INTERVENTION IN CALCIFIED CORONARY LESIONS: A 2 YEAR, SINGLE CENTRE EXPERIENCE}

H Muragagha, K Millar, B Wei Soh, I Ullah, T Hennessy, S Arnous, T Kiernan. University Hospital Limerick, Ireland

\subsection{6/heartjnl-2021-ICS.24}

Background Calcified coronary lesions are attributed to multiple risk factors such as increasing age, smoking, DM, and CKD. PCI of calcified lesions is challenging due to impaired stent crossing, under-expansion, and mal-apposition. Shockwave intravascular lithotripsy (S-IVL) is a novel angioplasty balloon that emits sonic pulsations, thus disrupting intra-coronary calcium and often obviates the need for conventional rotational atherectomy (RA). There is limited real-world data available on the use of S-IVL and we aim to review its use in our center.

Methods A retrospective single-center cohort study was performed of all S-IVL cases between Sep 2018 and Apr 2021.

Results Thirty-seven S-IVL procedures were performed during the period of the study. The mean age is 72.32 years (range 65-87, Median age 74).76\% were male. All patients had moderate to severely calcified coronary artery lesions. Indications for PCI included: 24 unstable angina, 9 NSTEMI, 3 Stable CAD, 1 ST-elevation MI, and 2 recurrent ISR despite drugeluting balloon therapy Risk factors included: $11(29.7 \%) \mathrm{DM}$, 34(91.8\%) HTN, 32(86.4\%) dyslipidaemia, 9(24.3\%) active smoking, 7(18.9\%) CKD, 2(5.4\%) previous TIA, 3(8.1\%) previous CABG and $13(35.1 \%)$ previous PCI. All lesions were post-dilated, mainly by using a $3.5 \mathrm{~mm}$ diameter; high pressure was also applied in almost $90 \%$ of post-dilation balloons. IVUS was used in 5 cases (mainly in LM procedure) to 